\title{
WHY HIGH SCHOOL STUDENTS IN CHILE, NOT ACHIEVE SIGNIFICANT LEARNING IN CHEMISTRY
}

\author{
M. CUBILLOS* \\ Pontificia Universidad Católica de Chile, Facultad de Química, Av. V. Mackenna 4860, 7820436, Macul, Santiago, Chile.
}

(Received: July 30, 2013 - Accepted: November 28, 2013)

\begin{abstract}
Most of the people who taught chemistry at university level, or secondary, arises as the question of whether their students learn all you are taught. The answer to this question is always the students learned very little.

From there, it is logical to wonder then why? The answer focuses on specific teaching of chemistry, showing the different problems of the teaching of this discipline. Among them raises the preconceptions that students bring, mathematization of chemistry, emergent properties and different levels of representation: macroscopic, submicroscopic and symbolic.

It is suggested that those who teach chemistry should keep these issues when teaching specific content and try new methodologies and in the future a profound change to the curriculum. Thus, it is proposed here to promote these changes, while modifying the high school curriculum is made, to redress initial chemistry courses in college and taking measurements to provide a basis and endorse the proposed amendments urgent curriculum.
\end{abstract}

Keywords: teaching chemistry, intuitive ideas, models.

\section{INTRODUCTION}

Many of us who teach General Chemistry at college-level, are surprised because that first-year students of different races have not achieved meaningful learning in chemistry after the four year of high school or middle school. It is a reality that all students review the contents of General Chemistry programs, but do not possess the ability to relate different topics of chemistry, not for lack of study or knowledge, but because they were no taught to perform this important cognitive operation ${ }^{1}$.

Specific didactic studies have reported that in Chemistry precisely one of the main problems in teaching discipline, corresponds to a piecemeal knowledge delivery, preventing students to integrate the three levels: macroscopic, microscopic and symbolic ${ }^{2,3}$.

Other important issues are the lack of understanding of the meaning of language (technical and everyday or common) and two misconceptions ${ }^{4}$, among others.

Another important factor that hinders student learning is the mathematization of the discipline over the conceptual understanding of different contents ${ }^{5}$.

This paper aims to discuss the issues mentioned, seeking to understand how their ignorance on the part of students and teachers, affects the achievement of significant learning.

Pre-concepts

Education in our country is based on a learning model in which students construct their own concepts ${ }^{6}$. According to this model, students generate their own meanings, based on history, attitudes, skills and experience. In this context become important preconceptions that students bring, because if they are not modified, will continue to maintain conceptual errors ${ }^{5}$.

As stated above, students must construct their own conceptions, therefore their constructions of a chemical concept sometimes differ from that of the instructor or teacher and has tried to present.

Some authors ${ }^{7}$ have described these different concepts as preconceptions, misconceptions, among others. For example, many students perceive the balance as strictly algebraie equations without considering the interatomic bonds rupture and formation of new bonds during a chemical reaction ${ }^{8}$.

This definition of pre-concept is relatively new in chemistry ${ }^{9}$, but widely studied in other areas of science such as biology and physics ${ }^{10}$.

\section{The Triplet Chemical}

The chemical knowledge is based and is represented at three levels: macroscopic, submicroscopic and symbolic (called triplet Chemical), at these levels has been based chemical education in the past quarter century ${ }^{11}$. Students usually learn from the subatomic level to the macroscopic level, as a linear progression, step by step, without even sometimes learn the symbolic ${ }^{3}$.

In Chemistry, students must connect observable phenomena, existing models of matter and the symbols we use to represent them, without having prepared for it. In addition, they are asked to relate submicroscopic models to describe, explain and predict structure and properties of different substances at different scales and dimensions. For example, in a chemical reaction a visible change is produced, which is seen as a color change, gas evolution, etc. (macroscopic). The observation of a chemical expert relates to the microscopic level, to infer that for the reaction to occur, there must have been breaking and bond formation, can relate, too, with a possible reaction mechanism that accounts for a established model (microscopically). Furthermore, it can be write the balanced reaction (symbology).

Unfortunately, this type of connection is not present and it is not easy to build in the minds of most of our students ${ }^{11}$.

Emergent Properties

This analysis did not yet mentioned anything about emergent properties of the new compound formed after a chemical reaction: physical property (color, melting point, etc.), which will be different from the properties present in the reactants of the reaction. This further confuses students, because they can not predict the physical properties of the new compound formed ${ }^{12}$.

Many students believe that the physical and chemical properties of atoms and molecules formed in a chemical reaction is the result of the weighted average of the properties of the initial components of the reaction. This can clearly illustrate by the color of a reaction product between reactants yellow and blue: students report that should be green, as well as they consider that the polarity of a molecule should be increased with the number of atoms in the system electronegative ${ }^{13}$.

\section{Mathematization on the Concept}

We all know that Lavoisier was the father of modern chemistry and that he began chemical quantifications due to his friendship with Laplace. All theories of Lavoisier require rationalization of Chemistry and in the future would interest only chemical materials that could be weighed or measured. In this way, we move away from chemical basics and we strive to quantify and measure each of the realized experiences.

One of the greatest physicists of the twentieth century, Niels Bohr (1955), wishing to emphasize the great role of mathematics in the development of theoretical natural science, said that it is not only a science, but the language of science ${ }^{14}$. No doubt, when Bohr was referring to mathematical language, took into account the language in a broad sense, ie he considered it as a means of expression of scientific thought.

Our students need to approach the basics concepts, understand, for example, what is a compound, a solution, etc., to reach a better understanding of observable events and then quantify.

Now the question arises: what can we do to help our students achieve meaningful learning?

In reviewing the textbooks commonly used in introductory chemistry courses, it is found that these topics are covered in a way outdated, with old approach submicroscopic models of matter: in most texts, the presentation begins with a discussion about the atomic nature of matter and the description of its main components, followed by the quantum model, electronic configuration, 
chemical bonding, etc. This sequence follows a linear progression, step by step, from the subatomic level to the macroscopic level of description and analysis of chemical systems.

For this reason, several authors have made educational research, introducing the topics suggested starting with an analysis of the macroscopic world, allowing students to build models submicroscopic to explain the experimental observations ${ }^{15}$.

New curricula are proposed, innovative books are published, proliferate web for teaching proposals, etc. One can be optimistic, but it should also recognize that what has changed is the presentation of topics without a profound change in the conceptual content ${ }^{16}$. It is urgent to recover the explanatory power of chemistry, for all, for to be related to practical chemistry and to contribute scientific literacyPerforming these changes is virtually impossible without profound changes to our school curriculum, which as we all know, is a curriculum saturated of contents. So, while achieving to promote a real modernization of high school curriculum, it can be try to address the issues presented here, in the way is currently proposed, testing new methodologies in introductory chemistry courses at the University, making measurements to quantify its impact on learning achievement, to provide specific data to substantiate the urgency to modernize programs and teaching methods in chemistry to promote a better understanding and use of our important discipline.

Among these new techniques it is necessary to mention that the author Mercé Izquierdo raises: "contextualize and subsequently modeling contents" ${ }^{16}$. Other authors mention conversations with students in small grups ${ }^{17}$, computer simulations of pre-review of theory content to endorsing such practices for students, in conjunction with analysis, discussion and conclusions (under implementation in Experimental Practice of General Chemistry Laboratories at PUC).

\section{DEDICATION}

This paper is dedicated to Dr. Elsa Abuin (RIP), to whom I express not only my admiration and respect, but especially my gratitude for allowing me to work with her at the postdoctoral and learn that his greatness was not just as outstanding scientist, but also an excellent teacher and above all a great person.

\section{REFERENCES}

1. A. Castillo, M. Ramirez and M. González. Omnia Año 19, 2,11 (2013)

2. F. Morugán, Didáctica de la Química. Capítulo 1 del libro "Química y sociedad. Un binomio positivo". Ministerio de Educación y Ciencia. Edita secretaria General de Educación, España 9, (2005).

3. V. Talanquer, Int.J. Sci. Educ., 33, 2, 179, (2011)

4. M. Nakhleh, J.Chem. Ed. 69, 3, 161, (2009).

5. Estándares Orientadores para Carreras se Pedagogía en Educación media, Ministerio de Educación Gobierno de Chile, Estándar 2 Libro de Química, área del conocimiento científico y su aprendizaje, pag. 214.

6. http://www.mineduc.cl/index 5 int.php?id_portal=47\&id contenido $=17116 \&$ id seccion $=3264 \& \mathrm{c}=1$.

7. P. Gamete, Gemetf P., D. Treagurt, J. Sci. Edue 12, 141, (1930).

8. R. Ben-Zvi, B. Eylon, B, Educ in Chem 117, (1987).

9. V. Talanquer. Series Innovations in Science and Technology Education, Vol. 19, 331. Springer: Dordrecht (2013).

10. L. Mora. Revista Colombiana de Física, 43, 3, 577 (2011)

11. V. Talanquer, EduQ número 5, 11, (2010).

12. V. Talanquer, Educación Química. 16(4), 114 (2005)

13. V. Talanquer, International Journal of Science Education, 31(15), 2123 , (2009).

14. R. Crespo, O. Martinez. Revista Electrónica de Investigación y Postgrado. Universidad Experimental de los Llanos Centrales "Romulo Gallegos", año 2, número 2, (2013).

15. V. Talanquer, EduQ número 5,11, (2009).

16. M. Izquierdo. The Journal of de Argentine Chemical Sociaty, 92, 4/6, 115. (2004).

17. V. Talanquer. JJ. Chem. Educ. 90, 1123 (2013). 